\title{
Traditional Batik Tuban Innovation Through Motive Development Using jBatik Software
}

\author{
Fajar Ciptandi \\ Study Program of Textile Craft and Fashion, Faculty of Creative Industries \\ Telkom University \\ Bandung, Indonesia fajarciptandi@telkomuniversity.ac.id
}

\begin{abstract}
The element in society's traditional batik's cloth's visual at Tuban, East Java, has character of vital importance in giving identity for society's tradition at Tuban. Motive's forms that described in traditional batik's cloth Tuban even also is some objects that often met by society at the everyday's environment. Besides, traditional batik's cloth Tuban also has been the witness towards history's trip Tuban with having culture's dialog with foreign's culture that brought by that time's international tradesmen passes acculturation's process. But such, in condition in this time where does technology's character and information has had so strong, as indirectly join in to give intervention towards tradition makes traditional cloth. Thereby had been opened possibility of the happening of reshuffle in visual's form and the meaning of special traditional batik's cloth Tuban.

According to the condition in which involved, the approach of this experimental methodologies will be held society's traditional batik's motive's design's development's experiments with will involve design's technology's to create motive (named jBatik Software) to see to how adaptation's level and also tradition's resistance makes society's traditional cloth Tuban. The ending conclusion can be made as a recommendation in continuation's efforts that will be done to develop special traditional cloth's design Tuban without disappearing the tradition's enthusiasm.
\end{abstract}

Keywords : batik, innovation, jBatik, motive, Tuban

\section{INTRODUCTION}

Traditional cloth in Indonesia is not only merely usual textile's sheet, but also created as the basic of ritual need, all of which is made by using weaving technic, using batik, and tied. Through the inheritance that is done by local people to the next generations in continuously, it causes the traditional cloths can still exist until now. But, it cannot be denied that in the inheritance process also there many things occurs the changes of them (value, function, and aesthetic) intentionally or unintentionally.

The traditional artifact at Tuban is gradually experience the reshuffle by placing the making of tradition making traditional cloth at Tuban in condition, among others: the weak full comprehension philosophical values found on cloth that is demoed with more decrease it cloth's use in also ritual, form aesthetical traditional cloth now more blooms up at free 's creation and dynamic, happens change in behavior and habit in big part of worker, with more increasing batik's worker that transfer to dyes technique uses synthetic dye's kind. The change in tradition's order is a normal thing, but still it constantly requires an attention in order that the change that happens will not cause the loss of identity element belongs to the tradition. Focusing is necessary thing to be done not only by the limit of giving innovation in traditional artifact, but it is also necessary to look at correct strategy for permanent display characteristics' specification that has by tradition.

\section{LITERATURE REVIEW}

\section{A. Study to Previous Research Relevant with this Research}

The Research about batik cloth's study and textile gedog had been known ever canvassed previously by a Dutch's origin researcher Rens Heringa in the year of 1994 who focussing in tradition of making cloth at Tuban at Kerek district, be one from 20 districts that exists in Tuban regency and be batik gedog center. In the watchfulness Heringa explains about how a cloth made in the way of traditional by society at Kerek district, by introducing the motive's kinds that be individuality for the region.

Heringa also elaborate the connection between cloth with Kerek's society traditional behaviour, with the hook towards philosophy that consist in at the opposite of cloths. Batik's cloth and textile gedog has not only various value of the matter, but also has values has non-thing. Textile that bloom at has cosmology's concept by local society is called as "Cycle of life" (Heringa, 2010: 42).

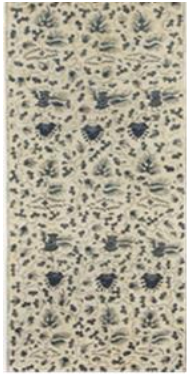

(a)

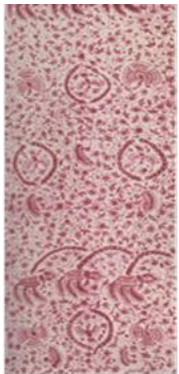

(b)

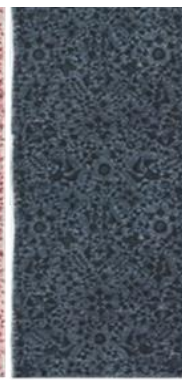

(c)

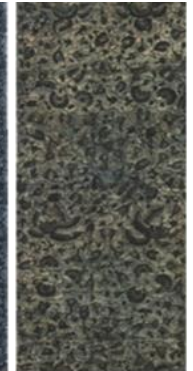

(d)
Figure 1. Traditional Textile Color and The Cosmology Concept of Tuban's society

Quoting Ciptandi (2018) Batik putihan (a) is dominated with white colour, according to society's erudition of Tuban people tha it is a symbol of the beginning of birth in which human borns in a state of clean and holy. So even also the things of with batik irengan (d) that dominated by black colour, this matter is correlated to their comprehension that while death and end life is deputed in dark colour's nuance and thick. Then between putihan and irengan found red/bangrod (b) and blue/biron (c) that believed by Kerek society as colour that symbolize about fertility and a life. 
Special decoration kind of traditional Tuban batik is known quite a lot in amount. In studying about the meaning and decoration kind of variation, decoration kind of fame, and the origin of decoration kind, the explanation which is collected by oral tradition to executant of batik maker that still survive until now.

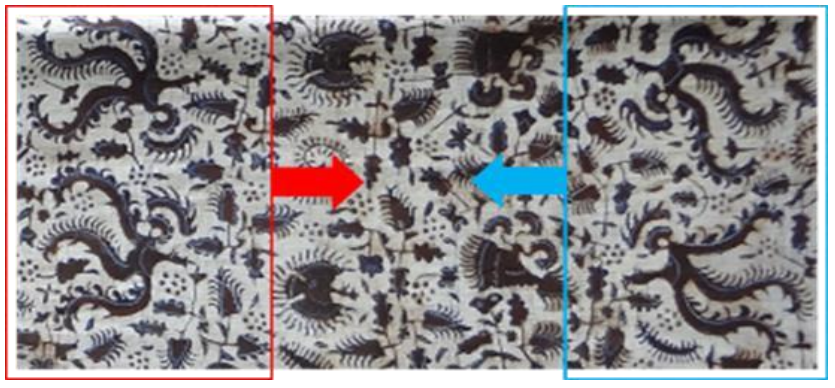

Figure 2. Motive Composition in an Opposite-line

\section{B. Software of jBatik}

Software of jBatik based on (Hariadi, et al, 2013: 84-85) is actually an application concept of fractal in batik, as has not been something intentionally, instead of passing series of researches' process by doing dimensional calculation fractal so at the end it can be proved that that there found some fractal elements in batik. The fractal character's existence in batik explainable with realizing beforehand character from fractal itself, that self-similarity (resemblance with self-form), mean found in detail geometry in scale smaller. As simplified to this concept explainable through the picture here:

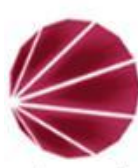

(a)

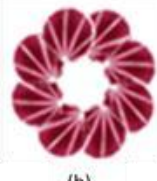

(b)

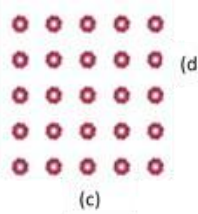

(c)

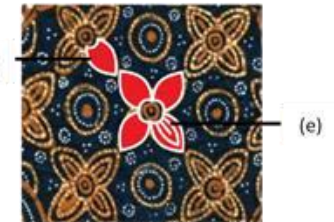

Figure 3. Fractal Elements in batik motives Ceplokan: Fractal of Sheath's Module Made Using jBatik (a), Flower Motive that consist of Sheath's Module form's reduplication fractal (b), Motive's Composition Ceplokan fractal by reduplication/in repeatedly (c), Flower Sheath's Module in Batik Ceplokan (d), flower's motive in Ceplokan batik formed from reduplication several flower sheath's modules (e).

By limiting the batik's explanation as a process of decorating cloth using canting and obstacle formed hot wax had made fractal batik as apart from of the definition.

Meanwhile, the existence of software jbatik in batik fractal has also made it as modern product oriented to innovation and newness. These two this matters show us that batik fractal, can be found that a condition where the tradition is able to sit in state with modernity (technology) collaboratively.

Fractal batik is still permanent using batik's word at in front of it to show that there are some values found as the principal principle from batik that stills permanent defended, that is process draws motive above cloth uses obstacle evening hot by using tool shaped canting. Although it is not formally, but it is agreed that if up to standard so a certain admission of to be called as batik.

\section{PROBLEM STATEMENS}

Besides imitated, tradition also experiences mutation slowly to present change in aesthetic aspect, function also meaning. But in the change, it is necessary paid an attention in order that the tradition's specification that is the identity of Tuban permanently able to be represented well. So, the collaboration between tradition which has conservative and inclined difficult in cooperating with technology, and modernity by producing newness and subsidized by technology's development; it is also necessary to do innovation's strategy in keeping existence and tradition's vitality towards trend of modernity and technology.

\section{METHODOLOGY}

Research method is done by doing a comprehensive approach strategy and experimentally. To understand the background of batik cloth's creation by the society of Tuban people as reference's source in do development, so it is held the ways of collecting data, as follow:

a. Literature study such as data collecting sourced from scientific journal, article, reference books that discuss tradition and traditional Tuban's cloth (authors: Rens Heringa and Judi Knight Acjhadi), researcher's individual note, and photo visual materials, sketches, and product's picture.

b. Direct observation at field to watch various data and phenomenon that occur at location, that is the central area batik maker and gedog's woven product at Tuban, precisely at Kerek district widespread at 4 villages, that is: Kedungrejo, Margorejo, Gaji, and Karanglo. Besides, also done in the form of observation towards interaction's patterns that in workers with cloth's maker process and cloth that is produced, to realize how traditional cloth's position at society in this time.

c. Oral tradition to get the testimony in form of speeches from tradition's executant that has explanation and information refers to previous generations. This tongue's testimony is held by doing interview process in long conversation and deeply enough to get the data and difficult information which is hardly found in textual source, but manifestly bloom in the middle of society.

By doing experimentally research which is done in various effort to batik's cloth through certain treatment's gift using software's jbatik then measured the influence's impact a treatment's variable towards impact's variable. This experiment's research is causality's research with the verification that is got by comparing the condition between the subject before it is given treatment and after it is given the treatment. In process of experiment's execution involve several batik's workers at Kerek. 


\section{RESULT OF ANALYSIS}

The process of motive's development has been done by jBatik software, there are 3 compositions of development motives. The process of experiment's execution involve several batik's workers to measure their adaptability to innovate.






\section{DISCUSSION}

The motive of special traditional batik of Tuban is the expression of traditional society in interpreting the values and the meaning which becomes the philosophy of their life, with the six senses as an important role in selecting the objects as the inspiration. For many years this kid of expression is able to survive, until at last to the condition like now the expression has faded replaced by the forms of creation's expression that is dynamic. Batik has no longer to bring along the values and the philosophical meaning of traditional, but rather can be freely created fit to the modern trend and lifestyle. Both of them cannot be placed directly opposite, because the fact is it can work together in synergy.

In facing the condition, so that the experiment will be done to the motive of special traditional batik of Kerek by giving the intervention in form of redesigned concept to the motive by involving technology role that is $\mathrm{jBatik}$ software to create the motive, in order that it will be able to show the new performance but still it brings the spirit the strong tradition. Besides, in doing the experiment process the local batik creators will be also involved whom chosen randomly and having the requirements of ability of making traditional batik technically to the gedog woven cloth, and so having the knowledge of the characteristic of traditional batik's motive in Kerek from the name of motive, shape, and colour. Finally, it is created the batik cloth which represents the mentality of special tradition of Tuban, but in the process of creation has occurred a collaboration with technology of $\mathrm{jBatik}$ software.

\section{CONCLUSION}

The series of research experiment has successfully the result of some points, these are the collaboration between traditional patterns in creating special batik cloth Tuban using the technology (jBatik software) to show that technology and tradition can work together in synergy without causing any meaningful conflict. Through the result of the experiment also it has be known today that the traditional sense of design is so strong in Kerek that the local identity is safe, despite modernization and the inevitable loss of the traditional role and significance given to cloths in the past.

\section{REFERENCES}

[1] J. K. Achjadi, N.A. Natanegara, "Tenun Gedog: The Hand-loomed Fabrics of Tuban, East Java", Media Indonesia Publishing, JakartaIndonesia, 2010.

[2] F. Ciptandi, A. Sachari, "Mancapat Concept on Traditional Cloth Cosmology of Tuban Community, East Java, Indonesia", Advanced Science Letters, 24(4), 2018, pp. 2243-2246.

[3] F. Ciptandi, "Transformation on Design of Gedog Weaving and Traditional 'Tuban' Batik Decoration Through Visual Characteristic Experiment", Doctoral Dissertation, Institut Teknologi Bandung, 2018.

[4] Y. Hariadi, M. Lukman, A. H. Destiarmand, "Batik Fractal : Marriage of Art and Science", Journal Visual Art and Design, 4, 2013, pp. $84-$ 85.

[5] R. Heringa, "Ninik Towok's Spinning Wheel: Cloth and the Cycle of Life in Kerek-East Java". Fowler Museum, Boston-London, 2010.

[6] A. Nugraha, "Transforming Tradition: A Method for Maintaining Tradition in a Craft and Design Context", Doctoral Disertation Aalto University, Helsinki- Finland, 2012. 